\title{
ESTUDO INVESTIGATIVO PARA DIMINUIÇÃO DA ACIDEZ DO PRODUTO OBTIDO A PARTIR DO CRAQUEAMENTO TERMOCATALÍTICO DO ÓLEO DE PALMA.
}

\author{
F. T. S. B. OLIVEIRA ${ }^{1}$, D. E. L. LHAMAS ${ }^{2}$, M. C. SANTOS $^{2}$, N. T. MACHADO ${ }^{3}$, L. E. P. \\ BORGES $^{4}$
}

${ }^{1}$ Universidade Federal do Pará, Faculdade de Engenharia Química

${ }^{2}$ Universidade Federal do Pará, Pós-Graduação em Engenharia de Recursos Naturais

${ }^{3}$ Universidade Federal do Pará, Faculdade de Engenharia Química

${ }^{4}$ Instituto Militar de Engenharia, Química

E-mail para contato: felipe.stabrigida@outlook.com

\begin{abstract}
RESUMO - O esgotamento gradativo das fontes de energia de origem fóssil aliado à crescente preocupação ambiental tem estimulado a busca por fontes energéticas alternativas. Diante deste cenário vários pesquisadores vêm investigando rotas tecnológicas que possam ser empregadas na produção de biocombustíveis com destaque para o craqueamento termocatalítico, uma vez que este processo apresenta flexibilidade de matérias-primas e os produtos obtidos são similares na composição ao diesel de petróleo, no entanto, este processo apresenta como desvantagem o elevado índice de acidez dos produtos obtidos, devido à formação de compostos oxigenados. Neste contexto, o presente trabalho tem como objetivo realizar um estudo investigativo, visando à diminuição do índice de acidez do produto obtido a partir do processo de craqueamento termocatalítico do óleo de palma, através dos processos de neutralização, destilação, extração líquido-líquido e blend. Foram realizadas análises de índice de acidez para o produto líquido orgânico bruto e para os produtos submetidos a cada processo de tratamento.A partir dos resultados pôdese verificar que a neutralização apresentou notável diminuição do índice de acidez em relação aos outros processos, portanto esse tratamento pode ser considerado o mais eficiente para a diminuição da concentração de ácidos graxos livres do produto líquido produzido no craqueamento.
\end{abstract}

\section{INTRODUÇÃO}

O histórico do uso de óleos vegetais puros em motores de combustão interna remonta ao início da operação dos próprios motores diesel, no final do século XIX, pelo engenheiro Rudolph Diesel (Oliveira, 2004). No entanto, até as "crises do petróleo" (1973 e 1979), não havia interesse na utilização de outras formas de combustível. O esgotamento gradativo das fontes de energia de origem fóssil aliado à crescente preocupação ambiental tem estimulado a busca por novas fontes geradoras de energia.

Diante deste cenário, a comunidade científica mundial vem se mobilizando com o intuito de encontrar rotas tecnológicas que possam ser empregadas na produção de biocombustíveis, com destaque para o craqueamento, haja vista que neste processo podem ser utilizados desde óleos in natura, gorduras, óleos residuais e subprodutos. Este tipo de 
tecnologia tem vantagens significativas sobre a transesterificação, incluindo os baixos custos de processamento, a compatibilidade com a infra-estrutura/motor e flexibilidade de matériasprimas. Os produtos finais são similares aos presentes na composição do óleo diesel de petróleo (Junming et al., 2010).

O processo de craqueamento ou pirólise de triglicerídeos consiste fundamentalmente de uma reação de quebra das cadeias carbônicas dos triésteres de origem animal ou vegetal pelo aumento da temperatura do sistema, resultando em uma mistura de compostos constituída, em sua maioria, por hidrocarbonetos lineares de diferentes pesos moleculares (Ma e Hanna, 1999). Os produtos do craqueamento incluem parafinas e olefinas cíclicas e lineares, além de produtos oxigenados, tais como ácidos carboxílicos, cetonas, aldeídos, ésteres e acroleína (Maher e Bressler, 2007).

No craqueamento de triglicerídeos, distinguem-se dois processos baseados no mesmo princípio, mas com características diferentes: o craqueamento térmico, que ocorre na ausência de catalisadores, sendo, portanto o aquecimento o único efeito responsável pela quebra das ligações químicas e o craqueamento catalítico, o qual é caracterizado pela presença de catalisadores, podendo proporcionar um melhor controle dos produtos obtidos, favorecendo determinadas rotas reacionais e conseqüentemente alterando a composição final dos produtos, permitindo maior seletividade e, portanto, maior rendimento dos produtos desejados (Lhamas, 2013).

Embora o craqueamento tenha inúmeras vantagens, este processo apresenta como principal desvantagem o elevado índice de acidez dos produtos obtidos, devido principalmente à presença dos compostos oxigenados no produto final, desta forma, faz-se necessário a realização de tratamentos para a diminuição da acidez, tais como a neutralização, Blend, extração liquido-liquido e separação de misturas por destilação, as quais podem reduzir de forma significativa a presença de ácidos graxos livres no biocombustível produzido via craqueamento termocatalítico.

Dentro deste contexto, o presente trabalho tem como objetivo realizar um estudo investigativo, visando à diminuição do índice de acidez do produto líquido orgânico obtido a partir do processo de craqueamento termocatalítico do óleo de palma bruto, através dos processos de neutralização, Blend, extração líquido-líquido e destilação.

\section{MATERIAIS E MÉTODOS}

\subsection{Matéria Prima}

O óleo de palma bruto utilizado no processo de craqueamento foi fornecido pela ENGEFAR LTDA (Levilândia, Ananindeua, Pará).

\subsection{Procedimento Experimental}

O experimento de craqueamento termocatalítico do óleo de palma bruto em escala piloto, bem como os processos de neutralização, blend, extração líquido-líquido e destilação 
em escala de bancada foram realizados no Laboratório de Processos de Separações Térmicas (THERMTEK/FEQ/UFPA).

Craqueamento Termocatalítico: O procedimento experimental do craqueamento termocatalítico consistiu inicialmente na pesagem do catalisador carbonato de cálcio $\left(\mathrm{CaCO}_{3}\right)$, correspondendo a $10 \%$ em massa da matéria prima, posteriormente pesou-se uma massa de 50 $\mathrm{Kg}$ de óleo de palma bruto, a qual foi acondicionada em um tanque de polietileno com formato cilíndrico e capacidade de $200 \mathrm{~L}$. O óleo contido no tanque foi bombeado para um trocador de calor com forma geométrica cilíndrica de aço inoxidável e aquecimento por resistência elétrica com potência de $15 \mathrm{KW}$, após alcançar a temperatura de $200{ }^{\circ} \mathrm{C}$, o óleo foi direcionado para o reator de craqueamento de aço inoxidável com forma geométrica cilíndrica, com sistema de agitação mecânica e capacidade de $125 \mathrm{~L}$ de operação. Após o acondicionamento do óleo pré-aquecido no reator, ligou-se o sistema de aquecimento do mesmo fixando a temperatura de operação em $440{ }^{\circ} \mathrm{C}$, sob agitação constante de $150 \mathrm{rpm}$. O processo descrito acima pode ser compreendido a partir da Figura 1.

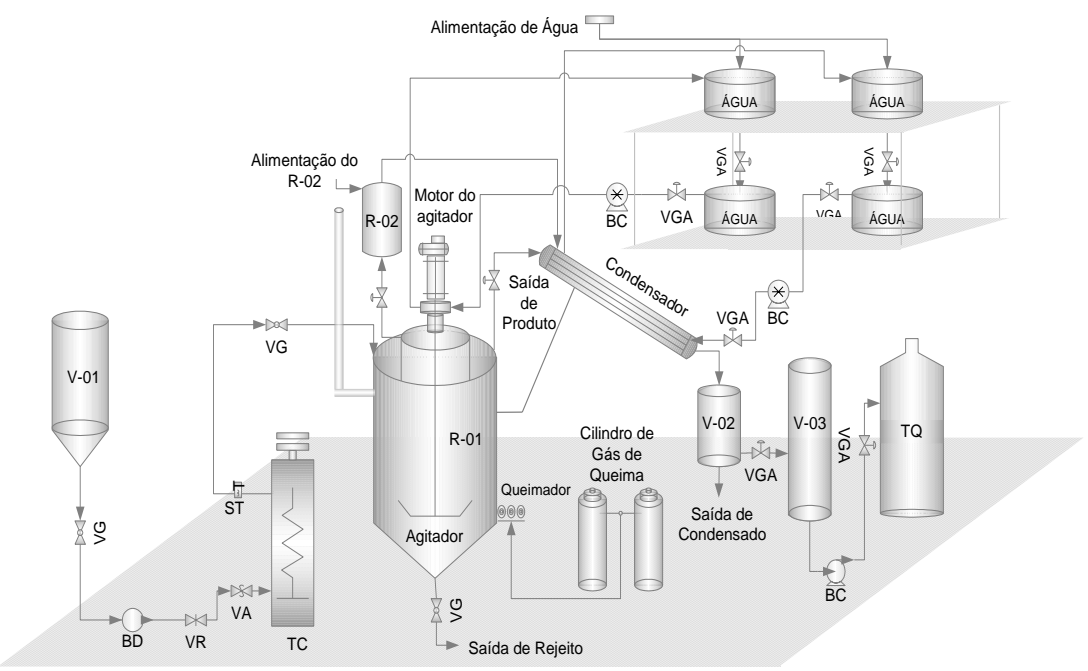

Figura 1-Planta de craqueamento termocatalítico.

Tratamento do Produto Líquido Orgânico: Com o objetivo de diminuir o índice de acidez do produto líquido orgânico obtido em escala piloto, foram realizados os processos de extração líquido-líquido, blend, neutralização e destilação, visando um produto final com baixo índice de acidez. Antes da aplicação destes processos no produto líquido orgânico, realizou-se uma decantação, filtração a vácuo e lavagem com água quente destilada a temperatura de $70{ }^{\circ} \mathrm{C}$. Estas operações foram necessárias em virtude da presença de partículas sólidas de catalisador no produto, provavelmente arrastadas pelos vapores através do sistema de condensação.

Destilação Fracionada:O processo de destilação em escala de bancada foi realizado, objetivando a obtenção de frações correspondentes a faixa de gasolina $\left(40^{\circ} \mathrm{C}-175^{\circ} \mathrm{C}\right)$, querosene $\left(175^{\circ} \mathrm{C}-235^{\circ} \mathrm{C}\right)$, diesel leve $\left(235^{\circ} \mathrm{C}-305^{\circ} \mathrm{C}\right)$ e diesel pesado $\left(305^{\circ} \mathrm{C}-400^{\circ} \mathrm{C}\right)$, de acordo com as faixas de temperatura descrita na literatura (Thomas et al., 2001; Szklo e Uller, 2008). O aparato experimental utilizado pode ser verificado na Figura 2. 


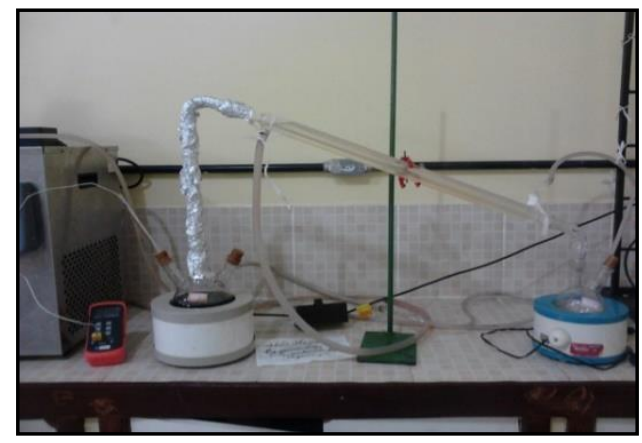

Figura 2- Aparato experimental utilizado na destilação.

Extração Líquido-Líquido: O processo de extração líquido-líquido utilizado para purificação do produto do craqueamento termocatalítico consistiu na utilização de água destilada e álcool etílico na proporção de 1:1 de produto craqueado e solução álcool+água, sendo a quantidade de água correspondendo a $20 \%$ em relação ao álcool, de acordo com Mâncio et al.; (2012). Na Figura 3 estárepresentado o aparato experimental utilizado na extração líquido-líquido.

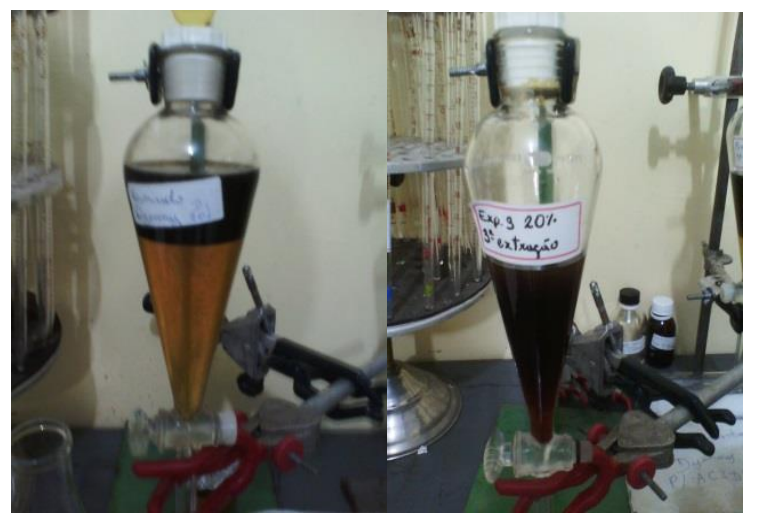

Figura 3- Aparato experimental Extração Líquido-Líquido.

Neutralização: A etapa de neutralização foi realizada em escala de bancada, utilizandose um reator de aço inoxidável encamisado (THERMTEK/FEQ/ITEC/UFPA), com volume de $3.000 \mathrm{~mL}$, acoplado a um banho termostático (Quimis, Modelo: Q-214M2) com controle digital de temperatura e um agitador mecânico (Fisatom, Modelo: 713 D), como ilustrado na Figura 4. Inicialmente, transferiu-se a carga do óleo para o reator. Estabilizou-se a temperatura em $50^{\circ} \mathrm{C}(323 \mathrm{~K})$ e a rotação em $600 \mathrm{rpm}$. Em seguida, gotejou-se com auxilio de uma bureta uma solução aquosa de $\mathrm{NaOH}$ por um período de aproximadamente 10 minutos. Após os 10 minutos, a mistura foi aquecida até uma temperatura de aproximadamente $60^{\circ} \mathrm{C}$ (333 K) seguida da diminuição da rotação para $90 \mathrm{rpm}$, objetivando-se a quebra da emulsão formada, permanecendo assim por 5 minutos. Após o término da neutralização o produto obtido foi transferido para um funil de decantação para separar as fases coexistentes líquidas (óleo) - líquida dispersa (emulsão), objetivando-se a separação do produto desejado do sabão gerado. Em seguida, foram realizadas, as operações de filtração e centrifugação seguidas do armazenamento do produto tratado. 


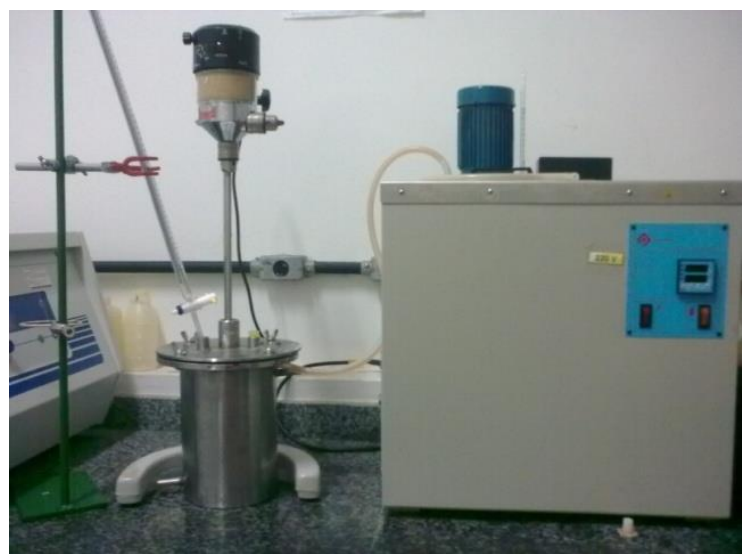

Figura 4- Aparato experimental de Neutralização.

Blend: Objetivando a redução do índice de acidez do produto líquido orgânico foram realizados blends com o diesel derivado de petróleo. As misturas foram preparadas pela adição de 10 e $20 \%$ de diesel de petróleo ao produto líquido orgânico em um funil de decantação, sendo a massa total da mistura utilizada de $150 \mathrm{~g}$. Após a formação do blend foram realizadas análises físico-químicas para a verificação da qualidade da mistura. A Figura 5 apresenta os blends de 10 e $20 \%$, respectivamente.

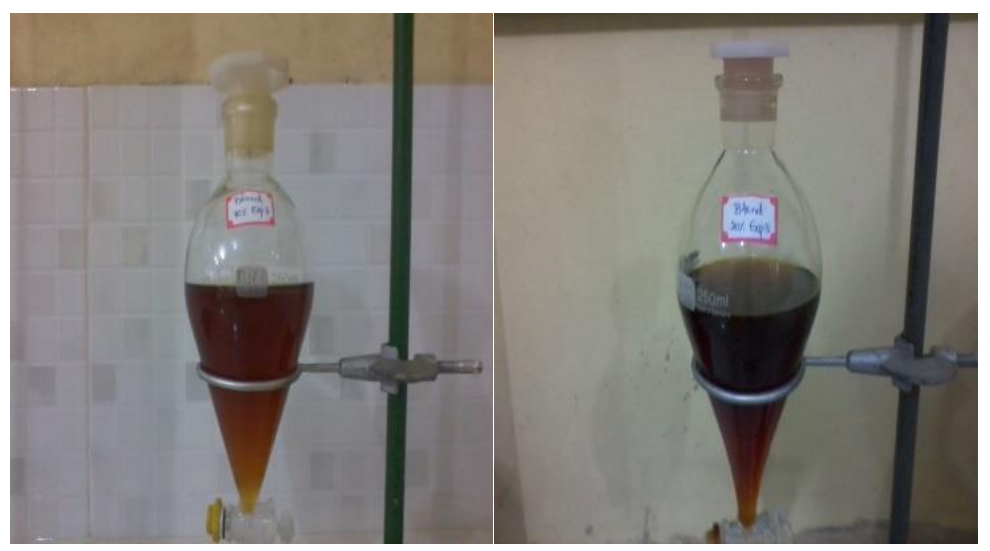

Figura 5. Blend a 10 e $20 \%$.

\subsection{Caracterização Físico-Química}

A análise do índice de acidez do produto líquido orgânico, assim como para cada produto obtido dos processos de tratamento de neutralização, blend, extração líquido-líquido e para as frações destiladas, foi realizado segundo o método oficial da AOCS Cd3d-63 (AOCS, 2001), no Laboratório de Processos de Separações Térmicas (THERMTEK/FEQ/UFPA).

\section{RESULTADOS E DISCUSSÕES}

De acordo com os resultados da Tabela 1 o produto líquido orgânico neutralizado apresentou notável diminuição no valor do índice de acidez de 1,60 mgKOH/g em relação ao valor de 22,60 $\mathrm{mgKOH} / \mathrm{g}$ do produto líquido antes da neutralização, demonstrando a eficiência da neutralização com $\mathrm{NaOH}$ (hidróxido de sódio) no processo via craqueamento termocatalítico. O processo de extração líquido-líquido também se apresentou eficiente, 
entretanto, foram necessários três extrações, para alcançar o valor de 6,33 mg KOH/g. Com relação as frações destiladas observou-se que acidez reduziu para as frações leves nas faixas de destilação de $40-235^{\circ} \mathrm{C}$, correspondentes as faixas da gasolina e querosene para diesel de petróleo e para as faixas correspondentes ao diesel leve $\left(235-400^{\circ} \mathrm{C}\right)$ e diesel pesado $(235-305$ $\left.{ }^{\circ} \mathrm{C}\right)$ a acidez aumentou. No processo de desacidificação referente aos Blends houve considerável diminuição do parâmetro analisado, com 4,16 mgKOH/g para $10 \%$ e 3,98 $\mathrm{mgKOH} / \mathrm{g}$ para $20 \%$.O blend apresentou maior diminuição a $20 \%$ de diesel derivado do petróleo.Desta forma, observou-se que dentre os métodos utilizados para a redução do índice de acidez, o que apresentou resultado satisfatório foi à neutralização do produto líquido, entretanto estudos ainda estão sendo realizados nesta área no Laboratório de Separações Térmicas (THERMTEK-UFPA), objetivando reduzir a acidez do PLO.

Tabela 1-Resultados do índice de acidez do PLO bruto e após cada tratamento

\begin{tabular}{c|c|c|c|c|c|c|c|c|c}
\hline Características & $\begin{array}{c}\text { PLO } \\
\text { Bruto }\end{array}$ & Neutro & \multicolumn{3}{|c|}{ PLO após a destilação $\left({ }^{\circ} \mathrm{C}\right)$} & PLO & Blend & Blend \\
\cline { 3 - 9 } & $40-175$ & $175-235$ & $235-305$ & $305-400$ & ELL & $10 \%$ & $20 \%$ \\
\hline $\begin{array}{c}\text { Índice de } \\
\text { Acidez } \\
(\mathrm{mgKOH} / \mathrm{g})\end{array}$ & 22,60 & 1,60 & 18,81 & 18,95 & 22,95 & 25,33 & 6,33 & 4,16 & 3,98 \\
\hline
\end{tabular}

\section{CONCLUSÃO}

Os resultados da análise do índice de acidez de cada tratamento permitiram caracterizar a neutralização como o processo mais eficiente na desacidificação do produto craqueado. Nesse processo de tratamento houve considerável redução deste parâmetro analisado, quando comparado com o produto líquido orgânico bruto, obtido no craqueamento. Nos outros processos de desacidificação a acidez também reduziu de forma significativa, porém em alguns casos é necessário repetir o processo mais de uma vez para se alcançar a acidez desejada. 


\section{REFERENCIAS BIBLIOGRÁFICAS}

AOCS - AMERICAN OIL CHEMISTS SOCIETY,5ed. Champaign, 2001. Section C: Commercial Fats and Oils, Cd 3d -63.

JUNMING, X.; JIANCHUN, J.; YUNJUAN, S.; JIE.; C. Production of hydrocarbon fuels from pyrolysis of soybean oils using a basic catalyst. Bioresource Technology. 101, p. 98039806, 2010.

LHAMAS, D. E. L. Estudo do processo de craqueamento termocatalítico do óleo de palma (Elaeis guineensis) e do óleo de buriti (Mauritia flexuosa l.) para produção de biocombustível. 2013. 219 f. Tese (Doutorado em Engenharia de Recursos Naturais)Universidade Federal do Pará. Belém, Pará, 2013.

MÂNCIO, A. A.; SILVA, R. A.; CORRÊA, L. H.; CURCINO, I. V.; MOTA, S. A.P.; ARAÚJO, M. E.; MACHADO, N. T. Desacidificação através da extração líquido-líquido da fração destilada na faixa de gasolina proveniente do produto líquido orgânico. In: Congresso Internacional de Bioenergia, 7, 2012. São Paulo. CD-ROM.

MA, F.; HANNA, M. A. Biodiesel production A review. Bioresource Tecnology, v. 70, p. 1$15,1999$.

MAHER, K. D.; BRESSLER, D. C. Pyrolysis of triglyceride materials for the production of renewable fuels and chemicals. Bioresource Technology, 2007, 98, 2351-2368.

MANDARINO, J. M. Gontijo. Tecnologia para produção do óleo de soja: descrição das etapas, equipamentos, produtos e subprodutos. Londrina. Embrapa Soja, 2001 40p. -(Documentos / Embrapa Soja, ISSN 1516-781X; n. 171).

OLIVEIRA, L. B.; COSTA, A. O. Biodiesel: uma experiência de desenvolvimento sustentável. Rio de Janeiro: IVIG/COPPE/UFRJ. 2004.

OLIVEIRA, F. T. S. B et al. Destilação Fracionada em Escala de Bancada do Produto Obtido do Processo de Craqueamento Termocatalítico do Óleo de Palma Bruto. In: Bioenergia, 2012, São Paulo 2012.

SZKLO, A. S.; ULLER, V. C. Fundamentos do refino do petróleo: tecnologia e economia. $2^{\mathrm{a}}$ Ed. rev. e ampl. - Rio de Janeiro: interciência, 2008.

THOMAS et al. Fundamentos de Engenharia de Petróleo. Rio de Janeiro: Editora Interciência, 2001. 267 p. 